\title{
Research Group Purchase Transaction Based on Dynamic Game
}

\author{
Xuyao Lin \\ Department of Business Administration \\ Fujian Jiangxia University \\ Fuzhou, China \\ 21901616@qq.com
}

\begin{abstract}
Group purchase as a new trading mode has been accepted by the public. But now there are many problems existing in group purchase transactions. Through establishing a dynamic model of group purchase transactions and analyzing the problems existing in the group purchase procedure, some corresponding solutions are taken, which helps the group purchase transactions conduct smoothly and promotes the market develop harmoniously and stably.
\end{abstract}

\section{Keywords- dynamic game ;group purchase}

\section{INTRODUCTION}

In recent years with the development of the Internet, network group purchase as a new e-commerce model is rapidly emerging. In November 2008 the United States group purchase site Groupon launched a new network group purchase mode, which set off an e-commerce boom in network group purchase. The goods and service launched by the network group purchase cover all aspects of people's lives, including catering, entertainment, beauty, garments, digital home appliances, furniture and other supplies. However, the survey shows that consumers don't sing high praise for the network group purchase overall. Only $16.16 \%$ of the respondents regard it as "satisfied", while over $80 \%$ of the respondents regard it as "general" or "unsatisfied". The reputation of the whole network group purchase is seriously affected. The credit problem has become a key factor which influences the further development of the group purchase.

\section{GROUP PURCHASE OVERVIEW}

"Group purchase is shopping by groups. It refers to a shopping way in which customers knowing or not knowing each other unite to improve the business negotiation skills so that they can obtain the optimal price."[1] From the transaction perspective, for one thing, many customers unite together can enhance the bargain ability between the customers and sellers. They can get the discounts to great extent and then get the needed goods and service by the optimal price. For the other, for the sellers, they can sell better via promotion. The more profit can be got by "small profits and quick returns". It can be seen that the group purchase is a "win-win" business mode for both customers and sellers. Therefore, it can be accepted by all easily.
Early group purchase is that some units and groups buy some household items together for the group welfare. Then some individuals organized spontaneously to purchase some particular product or service so that they can obtain some discount. It can be seen that as a commercial transaction mode, group purchase is nothing new. But the group purchase developed very slowly before the e-commerce developed, which was based on the Internet.

Though there are some successful cases in the early group purchase transaction, generally speaking, the majority of the cases are failure. The main problems in the early group purchase transaction are: Firstly, the information is seriously asymmetric. The information regarding price and the product quality which the customers can get is very limited, so it is difficult for the customers to make effective comparisons on price and quality and then calculate the cost and benefit in group purchase activities. Therefore, most of consumers don't make decisions before careful consideration. There is a big gap between the customer expectations and the reality during the transaction procedure due to their blind decision. The customer satisfaction is relatively low. Secondly, customers in the group purchase transactions are not an effective organization. The customer group is a temporary group formed by many customers knowing or not knowing each other. The structure of group members is complex. It is difficult for the group to restrict the group members' behavior. Thirdly, there is no effective communication between the group members. The communication between the group members is difficult. The group members are difficult to reach a consensus and take an effective common action.

The rapid development of Internet-based e-commerce and the rise of social media solve some problems in the early group purchase very well. It also brings a good opportunity for the group purchase development. With the rapid development of e-commerce, the problem of asymmetric information between Consumers and sellers has been solved well. Consumers can fully understand the market price and product quality information via e-commerce sites and they can effectively compare the prices. Through forums, micro-blog, instant message and other social media tools, the consumers communicate sufficiently and form more effective consumer groups. Thus, the network group purchase based on Internet and e-commerce, as a new group purchase develop quickly 
and popularly. The network group purchase draws more and more sellers and consumers' attention.

\section{ANALYSIS OF GROUP PURCHASE PROCESS}

Though the network group purchase is a good solution to the "information bottleneck" existing in the group purchase, compared with the traditional trading, there are still many problems in the group purchase. As a business model, group purchase process can be divided into three phases. The basic characteristics of these three stages can be summarized as follows: "Decentralized decision-making, group purchasing, separate consumption". That is, the consumer participating in the group purchase has independent decision-making power. They make consumption decisions according to their different judgments. When conducting transaction with the sellers, consumers are emerging as a group. But when the goods and services are delivered, the sellers are faced with different consumers. This basic feature of group purchase makes the group purchase transactions more complex than the traditional trading. And the transaction time is longer and the segment is more than the traditional.

As the feature of group purchase is "decentralized decision-making, group purchasing, separate consumption", group purchase is much more complex than the traditional trading. First, there is some relevance among group purchase transaction. In the traditional transaction, the trading between sellers and consumers is "one to one". Consumers are relatively independent. That is, a lot of trading between sellers and consumers is simple superimposition by "one to one" transaction. Any individual trading behavior change will not affect other transactions. Different from the traditional trading, group purchase is a "one to many" deal. In the group purchase transaction, a party to the transaction is a group of consumers. Any change of individual consumer transaction behavior in the trading will ultimately affect the entire transaction. That is, the trading between consumers and sellers is done one by one. Any trading between individual consumer and seller is just one part of the group purchase transaction. Only when the sellers and all the consumers complete the transaction, the entire group purchase completes. Secondly, the trading time span of group purchase transaction is long. For some group purchase transaction which provides service, the seller can't deliver the product to all the consumers at one time. They only can provide the service one by one during one period of time.

Long time transaction process and the decentralized but relevant transaction behavior require the group purchase transactions must be carried out under the effective restraint mechanism. Anyone involved in the transaction must consciously restrain their trading behavior, so that they won't affect the whole transaction and make sure the group purchase transaction can be conducted stably and effectively.

\section{STATIC GAME ANALYSIS OF THE GROUP PURCHASE TRANSACTION PROCESS}

In the group purchase transaction process, the main participants are consumers and sellers. Because at every stage, the group purchase transaction has its obvious characteristics, the model of complete information static game in the group purchase can be conducted by the game theory as follows:

\section{Assumptions:}

- Assume that the participants in the game are all rational economic man. In the group purchase process they pursue the maximization of the personal interests.

- Assume that the information in the game process is complete and perfect. The participants can easily get the market price of the goods or service. Both parties know the possible options of the other party.

- Assume that in the traditional sales, the market price of the product is $\mathrm{P}$, the cost is $\mathrm{C}$ and the corresponding demand is $\mathrm{Q}$.

- The seller and the consumer reach a group purchase agreement. The group purchase discount amount is $\triangle$ $\mathrm{P}(\triangle \mathrm{P}<0)$, the condition of getting a group is the number of the participants $q \geqslant N,(N$ is the assumed minimum sales volume getting a group) .

\section{A. Consumer Acting First Mode}

If consumers pay first, here refers to that all the consumers complete pay in the transaction and the sellers provide consumers with goods and services one by one. Then consumers have two options which is pay or not to pay. No payment refers to that the number of the consumers doesn't reach the condition $q \geqslant N$. So although the number of people with intentions more than $\mathrm{N}$, the number of people who actually pay is less than $\mathrm{N}$, the sellers won't provide goods and services. The group purchase can not be carried out. The game is over. The yield is $(0,0)$. If consumers choose to pay, the game goes on with the second stage. The sellers provide the consumers with goods and services one by one. Sellers can choose trade with faith or bad faith. If the sellers choose trade with faith, the both revenue is $(\triangle \mathrm{V}, \triangle \mathrm{U})$. The game is over. If the sellers choose trade with bad faith, that is, the sellers will get more profit by "shoddy" or "short weight" under interest driven. Then the sellers obtain additional revenue "a" from each consumer. The total additional revenue is aq. The corresponding loss of each consumer is a. The total loss is aq. Both of the income is $(\triangle \mathrm{V}$-aq, $\triangle \mathrm{U}+\mathrm{aq})$. Game is as s.11 ...

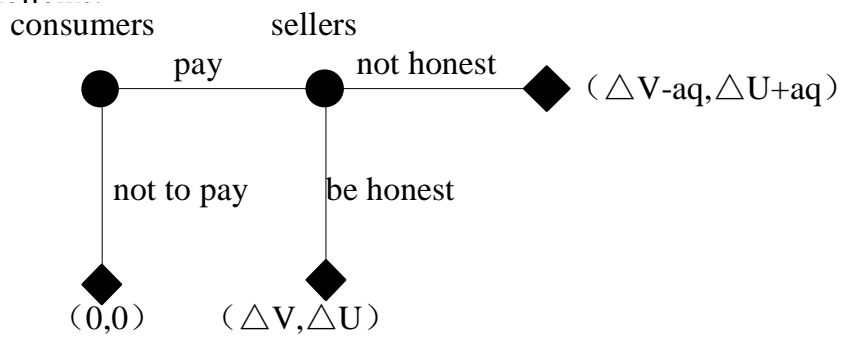

\section{FIGURE I. CONSUMER ACTING FIRST MODE}

For sellers, $\triangle \mathrm{U}+\mathrm{aq}>\triangle \mathrm{U}$, so sellers must choose with bad faith. When $\triangle \mathrm{V}$-aq $<0$ (that is: $\triangle \mathrm{P}$-a $<0$ ), consumers choose not to pay. Because sellers are rational, therefore they 
will choose "a" as big as possible, while consumers must choose not to pay. Therefore, the result of game is (not to pay, bad faith) and the group purchase will not be completed properly. From the above analysis: In the consumer acting first mode, transaction mode stability is dependent on the integrity of sellers and the consumer s' recognition on sellers' integrity. This situation can't restrict the sellers' behavior on the system level therefore the success possibility of the transaction is very low.

\section{B. Seller Acting First Mode}

If sellers provide the goods and service first and the consumers pay later, that is it is the same as the traditional one to one transaction. The sellers provide the consumers with goods and service one by one and the consumers pay one by one. Sellers can choose provide or not to provide goods and services. If the seller chooses not to provide goods, the group purchase can not be carried out. Both the revenue is $(0,0)$. If sellers choose to provide goods, the game goes on with the second stage. The consumers may choose trade with faith or bad faith. As consumers are in a group, every consumer may make strategy independently. The consumer choosing faith refers to every of each consumer choose with faith. The group purchase is successful. The both revenue is $(\triangle \mathrm{U}, \triangle \mathrm{V})$. The group purchase ends. If consumers choose with bad faith, here refers to some consumers do not fulfill their commitments resulting in bad faith happened to the whole group. Assuming that there are $m$ people with bad faith, the consumers' revenue is $\triangle \mathrm{V}+\triangle \mathrm{P} \bullet \mathrm{m}$. The seller's revenue is $\triangle \mathrm{U}+\triangle \mathrm{P} \bullet \mathrm{m}(\triangle$ $\mathrm{P}<0)$. Game is as follows:

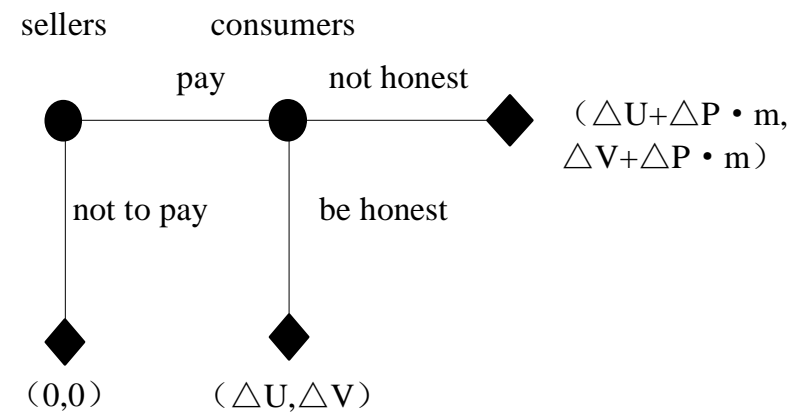

FIGURE II. SELLER ACTING FIRST MODE

Since $\triangle V+\triangle P \cdot m<\triangle V$, consumers choose integrity. Because $\triangle U>0$, so sellers choose to pay and the group purchase go on normally. But in fact, "the spontaneous group purchase" doesn't develop very well which launched by the consumers and sellers formed in the early stage. The analysis of the main reasons is: First, consumers are not completely rational. Because the group formed by the consumers has on effect restraint, the consumers will obey the rules due to all kinds of irrational factors, such as forgetting to deal with the transaction, going back in the half, etc. Secondly, from a rational point of view, the consumers participating in the group purchase will deal with fictitious group purchase by using the fictitious consumer information and won't meet the commitments when real consuming. Because if the group purchase can't be carried out, their revenue is 0 . If the group purchase can be carried out, their revenue is $\triangle \mathrm{P}$. Secondly, the consumers won't be honest if the find the lower price in the same products after they participate in the group purchase due to the insufficient inquiry before the group purchase. The reasons will result in the instability in the sellers acting fist mode of the group purchase. Only under the effect consumer managing circumstance, the group purchase can go on stably. From the above analysis we can see: In the two-partytransaction sellers acting first mode, there is no effect mechanism restraint taken on the overall consumer behavior due to the particularity of the consumers formed in the group purchase. Therefore, this mode is not stable and it can't guarantee the normal transaction.

\section{Three-Party-Transaction Mode}

In order to solve the integrity problem between the consumers and the sellers and form the restraint in the trading mechanism in the two-party transaction mode, normally the third party is pulled in to form the three-party-transaction mode. In the three-party-transaction mode, if the seller acting first mode is used, the third party will be faced with the same problem as the sellers. That is consumers' behavior can't be restricted. Therefore, consumer acting first mode is used in the three-party- transaction mode. In the three-party- transaction, consumers pay to the third party first so that sellers begin to provide the goods and service after the group purchase formed. The third party settles the account after they get the confirmation that the consumers have finished the consumption. The game is as follows:

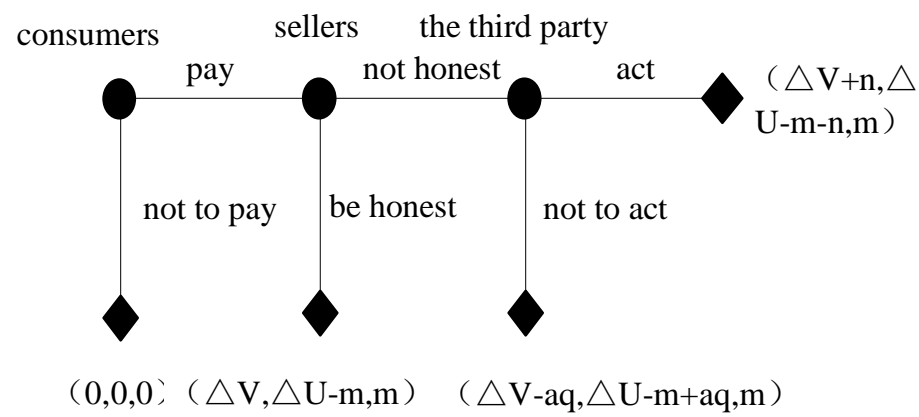

FIGURE III. THREE-PARTY-TRANSACTION MODE

At the first stage in the game, the consumers choose to pay or not to pay. If the consumers choose not to pay, the group purchase can't be carried out. The game is over. The revenue of three parties is $(0,0,0)$. If the consumers choose to pay, the group purchase is formed and it goes on with second stage. The sellers choose with faith or bad faith. If the sellers choose with faith, the game is over. The revenue consumers get in the group purchase is $\triangle \mathrm{V}$, sellers' revenue is $\triangle \mathrm{U}$-m. (Here assumed service fee $\mathrm{m}$ is undertaken by the sellers.) The service revenue gained by the third party is $\mathrm{m}$. The revenue of three parties is $(\triangle \mathrm{V}, \triangle \mathrm{U}-\mathrm{m}, \mathrm{m})$. If the seller chooses not to be honest, the game goes on with the third stage. The third party chooses to act or not to act. If the third party chooses not 
to act, the loss of the consumers is aq. The additional seller revenue revenue is aq. The revenue of three parties is ( $\triangle \mathrm{V}$-aq, $\triangle \mathrm{U}-\mathrm{m}+\mathrm{aq}, \mathrm{m})$. If the third party chooses to act and compensation $\mathrm{n}$ is paid to the consumer, which is deducted from the consumer payment, the revenue of three parties is $(\triangle$ $\mathrm{V}+\mathrm{n}, \triangle \mathrm{U}-\mathrm{m}-\mathrm{n}, \mathrm{m})$. For a single transaction, regardless of that whether the third party chooses to act or not to act, the revenue is $\mathrm{m}$. But in the long time view, the business reputation will be damaged if the third party chooses not to act. So the rational third party will choose to act. The third party choose to act, for the sellers, $\triangle \mathrm{U}-\mathrm{m}>\triangle \mathrm{U}-\mathrm{m}-\mathrm{n}$. That is the benefit of the integrity is greater than the benefit of bad faith. Therefore, the sellers choose the integrity and the consumers choose to pay. The balance result is (payment, integrity, action). From the above analysis we can see: In the short term, the involvement of the third party can't guarantee the stability of group purchase transactions mode. But in the long term, the third party can restrict the business behavior of the both trading parties effectively in order to ensure their own interests, which makes the group purchase transactions tend to be stable.

In the three-party-transaction and consumer acting first mode, the seller and the consumer's behavior are restricted so that the transaction mode can be carried out stably. As the mode is thee-party-transaction, although all the participants involved won't deviate from the balance separately, it can't be guaranteed that two parties involved in the game deviate from the balance, that is "conspiracy" risk exist in the three-partytransaction. If in the three-party-transaction, the third party reach "conspiracy" agreement with the sellers, for example, the seller gives the third party commission $\mathrm{h}$, the benefit of the third party choosing not to act is $\mathrm{m}+\mathrm{h}$, which is greater than the benefit of choosing to act $\mathrm{m}$. Then, the third party will choose not to act, the sellers will choose with bad faith and the consumers will choose not to pay. The original balance (payment, integrity, action) is broken and the balance result is (no payment, bad faith, no action). The group purchase can not be carried out. Therefore, the stability of three parties depends on the independence of the third party. That is, the third party must maintain the independence and impartiality so that the group purchase transactions can be carried out stably. Choosing an independent and impartial third party is the key to a smooth three-party-transaction.

\section{CONCLUSIONS AND RECOMMENDATIONS}

- The development of information technology promotes the development of e-commerce and social media, which is the necessary foundation to form a stable trading channel for the group purchase.

- In the two-party-transaction and seller acting first mode, the successful group purchase depends on the perfect consumer rational decision-making and credit system. But in the actual trading, it is difficult to restrict the consumer irrational behavior. Therefore, it is difficult to set up an effective trading mode.

- From the short term perspective, the three-partytransaction consumer acting first mode is not stable, but in the long term, it can form a stable transaction mode. Therefore, it can restrict the behavior of the transaction parties on the system level in order to ensure the stable and health conduction of the group purchase transactions.

- Despite from the long term perspective, the threeparty-transaction is a stable group purchase transaction mode. However, the three-party-transaction is still possible to result the "conspiracy" risk, which will lead to harm the consumers' interests. Therefore, the independent and impartial service party is important to the successful three-party-transaction mode in the group purchase. Corresponding management ways should be published and the behaviors of service party should be regulated in order to ensure the successful group purchase transactions. The management of the third party which is the service party in the group purchase should be strengthened so that the consumer interests won't be infringed.

\section{REFERENCES}

[1] "Group purchase". 〈http://baike.baidu.com/view/16979.htm.>.

[2] FeiXiaoyan." Network group-research based on game theory".Contemporary Economics.2011, (07): :110-112.

[3] Gefen D."Reflections on The Dimensions of Trust And Trustworthiness Among Online Consumers".Database for Ad-vances in Information Systems.2005,33 ( 3 ): 38 .

[4] Zhang weiying,Game theory and information economics,Shanghai:Shanghai people's publishing house,2004.

[5] Kauffman,R.J. and Wang,B., New Buyers'Arrival under Dynamic Pricing Market Microstructure:The Case of Group-Buying Discounts on the Internet,Journal of Management Information System,2001 